\title{
2. The digital divide in Papua New Guinea \\ Implications for journalism education
}

\begin{abstract}
Access to new technology and the development of the necessary skills to master them are crucial aspects when developing countries aim to play a more important role in the current information age and knowledge-based society. New technology and the internet have the potential to enhance access to information for people and to help countries such as Papua New Guinea become active producers of knowledge, shifting away from the traditional role of passive consumption. However, new technology also has the potential to increase already existing inequalities. In this regard, exploring the concrete shortcuts brought by the digital divide in PNG and trying to address them for journalism education is an imperative, so that journalists in the country can bridge this gap, raise their own voices and best contribute to the development of Papua New Guinean society.
\end{abstract}

Keywords: cyber-enthusiasts, cyber-sceptics, digital divide, digital literacy, digital media, ICTs, journalism education, Papua New Guinea, technology

\section{MARIA SAGRISTA and PATRICK MATBOB \\ Divine Word University, Madang, Papua New Guinea}

The information age does not have to be the age of stepped-up inequality, polarisation and social exclusion. But, for the moment, it is. (Castells, 1999, p.203)

T IS because of the internet that a human rights advocate in Papua New Guinea can get support from people all over the world, a New Zealander can buy African handicrafts from a dealer in Nigeria, or a father can watch his baby being born $20,000 \mathrm{~km}$ away. Since the general popularisation of technology and internet in the 1990s, it is clear that these two elements are having huge personal, political and economic implications for most people in this world.

However, the potential of the internet to bring about change can become a double-edged weapon for those who do not possess the access or skills to make use of the new technology. People who lack this access are in danger of becoming marginalised and excluded from the new information-based society. The gap between those who have access and those who do not is called the digital 
divide and it mainly affects people with less education, lower income, living in rural settings and developing countries. This article aims to clarify the concept of the digital divide, according to access, but also according to skills and use. The article tries to relate these concepts to the specific situation of Papua New Guinea by looking at the country's ICT infrastructure, internet penetration, costs and how users' information and structural skills allow an effective use of the net. Unfortunately, a lack of data regarding these factors does not allow a complete analysis of the current situation in the country. This article is, therefore, intended to be an initial foray into the topic which will also, hopefully, serve as a call for a much needed further research.

As the main aim of the article is to analyse the implications of the digital divide for journalism education and to envisage possible ways forward to develop the digital skills of future journalists, the article first explores the situation of higher education in Papua New Guinea and reflects on studies undertaken in other countries about the digital divide at the university level. It will be seen from the information obtained that many of the conclusions of these studies are applicable to Papua New Guinea. This provides a good starting point for reflection on what initiatives could be implemented to achieve higher rates of access and digital literacy that could allow Papua New Guinean journalists to become active producers of knowledge.

\section{Cyber-enthusiasts vs cyber-sceptics}

The internet is a system of communications that interconnects millions of users around the world, allowing them to access knowledge, share ideas and do business online. Defenders of the internet and the new technologies claim they have the potential to alleviate poverty, empower minorities, foster economic development and promote democratic principles (Shade, 2003, p. 107). For example, it was with the assistance of the internet and social media activism that former Egyptian President Hosni Mubarak was overthrown by a revolutionary wave of civil uprisings and demonstrations. On a similar note, the internet and social media played a big role supporting rescue teams on the ground after the impact of Typhoon Haiyan in the Philippines in 2013. These are only two cases that exemplify how technology and the ease of global connections can highly benefit people's lives.

However, many critics have highlighted the fact that the internet can increase social exclusion, posing a debate between two opposite positions: 'cyber-enthusiasts' and 'cyber-sceptics' (Shade, 2003, p. 112). Are the internet and the information and communication technologies (ICTs) alleviating or deepening inequalities? If the internet is defined as 'global', does 'global' also signify 'universal', meaning that everyone can and does have access to the internet? Cyber-sceptics strongly disagree. 


\section{The digital divide defined}

The world is changing at a lightning speed and we, as citizens, are required to keep up. What happens to those people who do not have access to these technologies? They are affected by the digital divide.

The digital divide is a term created in the mid-1990s (Yu, 2006, p. 236) to define the 'disparity between those who have access to the technologies and the internet and those who do not' (Shade, 2003, p. 108). This lack of access, mostly localised in specific groups, prevents them from exploiting all the advantages that the new information technologies bring, such as accessing jobs, promoting and expanding their business online, or providing a platform to raise their voices and opinions. Consequently, these groups have limited opportunities and are at risk of becoming marginalised from the rest of society.

This initial definition of the digital divide, based exclusively on lack of infrastructure and hardware, was expanded later on to include not only access to technology, but other factors such as the differences in use caused by socioeconomic disparities and different skill levels between people. This more comprehensive definition, sometimes also called 'the second divide' (Van Deursen \& Van Dijk, 2010, p. 908), moved beyond the superficial problem of access to consider fundamental social issues and brought to light a much more complex spectrum of reasons that need to be looked into when trying to mitigate the digital divide (Coleman, 2015; Selwyn, 2004; Van Deursen \& Van Dijk, 2010).

As Selwyn explains (2004, p.349), the fact that someone has access to information and communication technologies does not necessarily imply that this person will make use of them. It is easy to imagine a household with a computer and an internet connection where the different family members possess different skill and interest levels when it comes to engaging with the digital world. Even so, the members who do use the internet might not do so in a meaningful way that allows them to take full advantage of the benefits of the global net.

In this regard, the concept of digital literacy highlights the relevance of these new set of skills required to successfully take part in the societies of the new information age (Servon \& Nelson, 2001, p.279; Van Deursen \& Van Dijk, 2010, p. 894; Kolodziejczyk, 2012, p. 210; Radovanovic et al, 2015, p. 1737). Digital literacy is 'a twenty-first century form of literacy in which researching and communicating information via digital environments are as important as reading and writing were in earlier centuries' (Katz, 2007, p. 4). If access to and meaningful use of the internet and ICT empowers individuals by allowing them to establish wider social connections, increasing political and civic participation and promoting the access to education' (Selwyn, 2004, p. 342), the lack of access leaves people in a disadvantaged position of limited opportunities. 


\section{Research so far}

The research done on the topic of the digital divide shows that, while the original issue of lack of access and infrastructure is progressively being addressed, the more recently considered social, psychological and cultural aspects of the divide are increasing (Van Deursen \& Van Dijk, 2010, p. 894). Nowadays, the gaps are not so much caused by lack of connectivity or access to technology, as governments and international organisations are investing in extended networks and affordable technology. The socio-cultural differences, such as education level, location, gender, race, income, age, ethnicity or linguistic background (Reagan Shade, 2003, p. 108) are widening the gaps and making many wonder if there is any way to close the digital divide (Van Deursen \& Van Dijk, 2010, p. 909). In general terms, the digital divide exists between city-rural environments, educated-uneducated citizens, different socio-economic groups and developed-developing countries (Coleman, 2015, p. 145).

\section{Skills}

Which digital skills do people need to benefit from using the internet? According to Van Dijk \& Van Deursen (2010, p.895), there are four sets of abilities that internet users should have if they aim to fully engage with the digital world and get the best results out of it. These skills are grouped into two categories: those directly related to the medium and the ability to master the technical aspects of it, and those specifically concerned with the content searched and found.'

The medium-related skills are divided by Van Dijck \&Van Deursen into operational skills and formal skills. Operational skills are those that allow a person to make a basic use of technology and the internet, such as using different browsers, utilising search engines or filling out a form on a website. To complement these, the authors talk about formal internet skills, those abilities that are directly related to how the user navigates the net, understands where different content is located and how he or she can access them. These would include the ability to surf the net through hyperlinks and the ability to understand the structure of the different websites without getting confused or disoriented (2010, p. 896).

Beyond these medium-related internet skills, van Deursen \& Van Dijk, talk about information skills and strategic skills, more complex competencies which are directly connected to the way users deal with content and how they search and find information online (2010, p.895). Information skills are associated with the user's ability to fulfill his or her information needs by, for example, carrying out efficient searches and being able to assess the quality of the different results. On the other side, strategic internet skills are those that allow a person to use the information technologies and the internet as a means to reach a specific objective, which will contribute to improving one's position in society. 
In summary, operational skills are those related to the basic use of technology and the internet; formal skills are those concerning navigation and orientation; information skills are the abilities that allow the user to access the information she or he needs; and strategic skills have to do with the efficient use of the internet, and the achievement of specific targets and solutions that will have an impact on the person's status. Users around the word, between and within societies, possess different levels of digital skills. These skills, especially, information and strategic internet skills, strongly condition the position of people in their social life and in the labour market, as they are the ones that allow access and interaction with economic, social and political opportunities (Van Deursen \&Van Dijk, 2010, p. 908).

Do our journalism students, or students in general, possess these critical skills? Are they fully equipped to face the new demands of the digital world and keep up with the pace that 'progress' is imposing? Do our courses ensure that they do not lag behind missing opportunities?

\section{Who is included and who is excluded?}

Research on the digital divide has been trying to discover which factors differentiate those people who have access to the internet from those who do not. According to Selwyn (2004), 'access' is already a term whose definition should be carefully considered. Several other components affect the different degrees of access that users have, generating 'various shades of marginality' (p. 348) depending on the available time to connect to the net, cost of connection, quality of the technology at one's disposal and surrounding environment (p. 347).

Different kinds of research conducted within the past 20 years in several developing and developed countries (Yu, 2006, p. 238) have shown that specific patterns indicate who is 'connected' and who is not. In this regard, differences in access and use seem to be highly influenced by income, level of education, gender, race, age, geography, linguistic background and personal interest (Shade, 2003, p. 108; Selwyn, 2004, p. 344; Van Deursen \& Van Dijk, 2010, p. 899; Yu, 2006, p. 236). These factors will vary if the focus of attention is set on the global digital divide (differences between countries) or on the societal digital divides (differences within a country or a specific society). Discrepancies between countries have been found to be mostly related to 'economic development, education, information infrastructure, culture, policy orientation, costing structure for internet access, openness of the telecommunication market, level of urbanisation, the official language and the charging arrangement for internet interconnection' (Yu, 2006, p. 238). In relation to the societal digital divides, several authors have concludes that, contributing educational level, age and gender are the most relevant factors that contribute to the stratification of particular sectors of the population in relation to internet access and digital skills (Van Deursen \& 
Van Dijk, 2010, p. 899). Those with less education and those who are older are less likely to be connected (Radovanic et al, 2015, p. 1739).

\section{The situation in Papua New Guinea}

Papua New Guinea became independent in 1975. With an estimated population of 7.6 million people, it occupies the eastern part of the island of New Guinea, north of Australia. About 85 percent of the population live in rural areas, in scattered customary communities with diverse belief systems, cultural traditions, and distinct forms of social organisation. Most of these groups are isolated and inaccessible by road, depending on subsistence and small cashcrop agriculture. The other 15 percent of the population live in urban areas such as Port Moresby, Lae, Madang, Wewak, Goroka, Mt Hagen or Rabaul (DFAT 2015; WHO 2015; UNDP 2015, UN Data 2015, CIA 2015).

Papua New Guinea is considered one of the most diverse countries in the world, with more than 840 languages spoken, many of them with fewer than 1000 speakers. After independence in 1975, Papua New Guinea became a constitutional parliamentary democracy. PNG is rich in natural resources such as gold, oil and gas. This wealth has prompted an increasing interest from the extractive industries, especially with an intense boom over the past decade, during which the country has experienced an annual economic growth of 6.5 percent. Despite these numbers, poverty levels have not changed much since 1996, keeping the country within the 'low human development' category, ranking 157 out of 187 nations. Some of the reasons considered to explain this fact are the distribution of the population across rugged landscapes (which makes the delivery of government services very difficult); extremely low levels of literacy within the population (literacy rate for youth and adults range from 60 percent to 76 percent); the very recent exposure to health and education services in most parts of the country and a very limited government capacity (UNDP 2014: World Bank, 2009, 2011, 2015).

The 2014 National Human Development Report on Papua New Guinea concluded that the 40 years since independence, in which PNG's economy has been based on the extractive industries, have brought improvements in livelihood, health and education, but only for some. GDP per capita is US\$1767 and about 40 percent of the population lives on less than US\$1.90 a day (World Bank, 2015).

\section{Information and communication technologies}

How easy is access to internet and computer technologies for Papua New Guineans? How does this situation affect their wellbeing in relation to the potential opportunities that the new ICTs can bring? Given the isolation experienced by most rural dwellers, access to technology, internet and mail is mostly limited to towns and cities (Watson, 2009, p. 107). 
In regards to the information and communication technologies, Papua New Guinea liberalised the telecommunications market in 2007, creating an expansion of mobile phone signals to many rural communities which had been completely cut off from any phone coverage. It also generated a rapid increase in the ownership of mobile phones (Watson, 2009, p. 107; Suwamaru, 2015, p. 1), the only means these communities currently have to connect to the internet. Before that, the state-owned company Telikom PNG was the only provider in the country, with a very limited coverage mainly restricted to urban areas. With the sale of a new mobile license to Digicel, the mobile network quickly expanded throughout PNG (Watson, 2011, p. 250) and competition between companies originally increased the connectivity options for customers and reduced the prices.

A comparison of the World Bank data for 2015 regarding ICT infrastructure in PNG with New Zealand, demonstrates the extensive gap between developing and developed countries. While the current percentage of mobile phone subscriptions in Papua New Guinea after the expansion of Digicel to the rural areas is at 45 percent, in New Zealand it adds up to 112 percent, more than one mobile connection per person. On a second note, the number of fixed broadband subscriptions in PNG is 0.18 percent, practically nonexistent, while in New Zealand they account for 31 percent of the population. Knowing that only 3.6 percent of the households in the Melanesian country own a computer, versus 80 pecent of households in New Zealand, it is not surprising that the percentage of internet users in Papua New Guinea remains below 10 percent, while the average in New Zealand is about 85 percent. Of course, with the lack of connectivity networks and of few potential customers, the cost of a subscription to a fixed broadband internet connection in PNG is US\$446 a month, a price that almost no one can afford, compared with about NZ\$62 a month.

This data reveals deep, striking inequalities that puts Papua New Guinea in a very disadvantaged position when it comes to participating in the global contemporary society. In a world where so much knowledge is stored and transmitted in the digital sphere, countries and people who lack the appropriate facilities to access these resources and services are progressively being marginalised and deprived of opportunities.

\section{Higher education}

According to Kolodziejczyk (2012), before the school-based system, education in Papua New Guinea was aimed at introducing children to the appropriate gender roles they were assigned to perform in society. Traditionally carried out by the family and the community, this education had a strong ceremonial character. The first formal educational systems were established by Catholic and Protestant missionaries and by the German and Australian colonial governments. A broader education was established throughout the Territory of Papua and New Guinea 
by the Australiana administration in the decades following the Second World War. In 1966 the University of Papua New Guinea and Higher Institute of Technology were established. The first graduates of these tertiary institutions were able to enjoy multiple opportunities for employment as the country was going through a phase of economic and political expansion. Unfortunately, within 15 years the situation for graduates was much less favourable.

According to the Papua New Guinea Department of Higher Education, Research, Science and Technology (DHERST, 2015), the country now has 33 institutions of higher education, including six universities, four of which are public and two private (Rooney, 2004). A total of 31,000 students were enrolled in these tertiary institutions in 2014, which is only 2-3 percent of the estimated 600,000 young people of university age (17-24) (Tagis, 2010; DHERST, 2015). Some tertiary institutions do not have free internet access for students, computer availability is very limited and academic staff admit they have no experience with the internet. In addition, fewer than 40 percent of students own a computer.

Papoutsaki and Rooney (2006) highlight how the Papua New Guinean higher education system is based on Western models and standards, but lacks many of the necessary resources to make it work effectively (DHERST, 2015). There has been strong criticism of the higher education sector in the country, as it is accused of producing graduates who are not equipped with the necessary skills to contribute to the positive development that Papua New Guinea needs. In the PNG Universities Review from 2010, the most recent and comprehensive review of higher education institutions undertaken in PNG, this concern was made explicit: 'Right now, the quantity and quality of graduates is far short of what is needed - due to inadequate resources and a range of governance and general service quality issues' (Garnaut \& Namaliu, 2010, p. 1 in Kolodziejczyk, 2012, p. 22). Unfortunately, judging by the lack of educational policies and little economic investment, education does not seem to be a priority for the Papua New Guinean government (Bloom \& Rosovsky, 2006).

\section{Implications for journalism education}

If digital literacy is crucial to becoming engaged with the new information age and knowledge-based society, how are we educators in Papua New Guinea, integrating these new technologies into the teaching and learning practices?

There is very little published information on what is being done in PNG. However, Karthikeyan and Ramalingam (2016) explain the case of Divine Word University and its initial efforts to implement blended and online learning, with a university-wide introduction to computing and word processing. As necessary as it is to train university students on the use of new technologies, several factors make the incorporation of new technologies within a traditional face-to-face curriculum a very challenge. A study conducted by Radovanovic, Hogan and 
Lalic (2015) in Serbia can be used as an eye-opener to many of the difficulties that universities around the world face. Their conclusions may be applied to the situation of higher education in Papua New Guinea. These authors claim that digital literacy is a form of human capital deeply connected to the person's ability to understand the world and gather information $(2015$, p. 1735):

Digital literacy is the awareness, attitude and ability of individuals to appropriately use digital tools and facilities to identify, access, manage, integrate, evaluate, analyse and synthesise digital resources, construct new knowledge, create media expressions, and communicate with others, in the context of specific life situations, in order to enable constructive social action. (Martin, 2005, p. 135-136, in Radovanic et al, 2015, p. 1737)

According to Radovanovic, Hogan and Lalic (2015), access is a basic requirement for digital literacy, but access alone is not enough. Digital literacy needs to be learnt and this means that it needs to be taught. Precarious and uncertain infrastructure will be a drawback when trying to teach digital literacy in university classrooms, especially in developing countries, where in many cases there is a lack of computers, projectors and internet access in the lecture room. However, one of the main problems that is not so broadly considered is the educators' reluctance to accept the paramount role of new technologies. In many contexts, technology is seen as a threat by lecturers and professors, as it challenges the traditional power structure (p. 1733).

Radovanovic et al. (2015) explain how lecturers and professors possess a high level of education (one of the main factors that affects inclusion or exclusion within the digital divide), but this level of education is mediated by age. The fact that, in general, students are more computer literate generates power tensions and provides opportunities for students to displace the traditional status granted to the professor. Professors feel that technology reduces their authority and legitimacy, as students can easily question their knowledge and expertise with a simple Google or Wikipedia search, sources not validated by traditional academia. In addition, the introduction of new technologies in the higher education system requires educators to relearn abilities and skills, as ICT is constantly evolving, demanding that they invest a great deal of time and effort in becoming computer literate. In this regard, it seems that older generations of lecturers and professors are not teaching digital literacy skills to their students simply because they lack this kind of knowledge. Unfortunately, if professors do not use on-line resources, it means they are not transferring these digital literacy skills to the younger generations, leaving them ill-prepared for a personal and working life where technology is becoming increasingly omnipresent (Kolodziejczyk, 2012, p. 39; Radovanovic, et al, 2015, p. 1737).

There are many other challenges when introducing ICT and online resources 
into the university classroom, especially in developing countries such as Papua New Guinea. Besides unreliable infrastructure and the educators' reluctance and lack of knowledge, there are two other aspects that have a big influence on how successful the implementation of these technologies will be. The first one is the definition of appropriate pedagogy for online learning (Goh \& Kale, 2015, p. 308) and, the second one, how political power (management of educational institutions) understands and fulfills the needs of academics and students. Regarding this latter issue, Radovanic et al. concluded from their research that in many cases students and academics perceive management and political power as having completely different priorities. As management seems to focus much more on developing infrastructure and achieving a high technological standard for the institution, students and educators agree that more training is needed (2015, p. 1744). Learners and, especially professors, feel they are under pressure to cope with the latest technologies, while they are not properly equipped with training, support or time. The result is a lack of motivation and collaboration from educators, which really makes the development of online resources and e-learning tools difficult. Technology becomes then an obstacle rather than an aid.

According to the World Association of Newspapers and News Publishers (WAN-IFRA), there were 1.1 billion online news consumers in 2014. With so many users switching to, or combining, traditional media outlets with online news platforms, it is imperative that journalism schools reconsider their curriculum to adapt to the new requirements of the audience. The curriculum in journalism schools around the world is very much based on print journalism (Goh \& Kale, 2015, p. 308). Any lecturer should be focused on developing digital skills in students, but for journalism educators this becomes a real priority. Ideally, all university graduates should possess a set of digital competences that allows them to master computer and internet formal and operational skills, retrieve relevant information to achieve specific goals and analyse and create content online that lets them communicate digitally (Radovanovic et al, 2015, p. 1737). For future journalists, these skills would be indispensable tools (Goh \& Kale, 2015, p. 308).

According to Goh and Kale (2015), future journalists should learn all the essential principles of traditional journalism and, at the same time, develop multimedia competences that will help them work collaboratively, foster critical analytical skills, be resourceful and stay connected to the latest developments (p. 309). Trainers need to cultivate a 'multimedia awareness' in students and make sure they build up their expertise by producing relevant content across new digital media platforms. Unfortunately, journalism programmes seem to be slow in this transition to digital journalism, as this requires a fair amount of investment of time and resources to redo the curriculum, train academics, purchase equipment or work across platforms (p. 308).

Because of socio-economic and geographical circumstances, Papua New 
Guinean journalism students face many difficulties when it comes to becoming digitally literate and actively engaged with the global community. The access barrier is slowly being reduced and PNG seems eager to catch up with more advanced countries. Social media networks, especially Facebook, have become widespread with more than 350,000 registered users (Internet World Stats, 2015). The level of participation in PNG is extremely high, but do our students engage with the digital world beyond Facebook status updates and Candy Crush? Do they possess the information and strategic skills necessary to successfully participate in the global world? Unfortunately, in many cases, students and lecturers still have to answer 'no'. Further research to understand the causes and motivations of this situation and to support the implementation of an effective action plan is imperative.

\section{From passive consumers to active producers}

Another relevant concept for this topic is that of 'digital production inequality', introduced by Schradie (2011, p. 158). Despite the fact that his research mainly claims how differences in class affect people's ability to create online content, it illuminates the main elements affecting content creation. Being able to produce content gives people the opportunity to create and disseminate knowledge, but research has proven that not everyone creates online content. Why not? What are the factors that allow people to voice their opinions, express their perspectives and participate in global discussions? Again, it is easy to identify similar patterns to those affecting the original digital divide in regards to access and skills.

Future Papua New Guinean journalists need to have the ability to talk about their specific reality from their own cultural understanding, breaking the long-standing trend of content being generated by outsiders. It is time for these journalists to move from being passive consumers to active producers of knowledge and media (Shade, 2003, p. 111). They need to be equipped with the necessary skills to produce public discourse about political, economic or cultural issues and influence public opinion. In order to do this, journalists must become digital literates and need to develop a 'multimedia consciousness' (Goh \& Kale, 2015, p. 312).

\section{Suggestions for bridging the digital divide in PNG}

Drawing on Parent and Cruickshank (2009), it could be useful to consider or re-consider the role of libraries in Papua New Guinea. Libraries are traditional access points of information and in many countries they also play an important role for training, education and advocacy within the community (p. 94). Libraries in developing countries have a huge potential as facilitators of knowledge and information. In some countries mobile libraries with computers and internet access periodically visit remote and isolated areas (p. 94). These libraries could easily include an internet advisor who could provide training and assistance. 
On another note, due to the economic constraints experienced in developing countries, citizens have developed alternative ways of accessing technologies and the internet. With the rise and popularisation of the smartphone, especially in poorer communities, (Park \& Lee, 2015, p. 80), many people share devices and connections to access the internet (James, 2012, p. 183; Watson, 2011, p. 35). Promoting a culture of sharing, supported by local or regional institutions, could be a way to make internet and new technologies much more accessible to the general public.

Going back to the recommendations of Radovanic, Hogan and Lalic (2015), more institutional support should be provided for teachers and students. This would allow them to become proficient in digital technologies and more positive about the use of the new technologies and confident about their abilities. Training is imperative at all levels and encouragement and assistance are required to change many negative perceptions that are holding back the transition to the digital world. The authors also propose a mandatory first-year course on information retrieval for all university students (p. 1742), an idea that has been already partially implemented at Divine Word University.

Goh and Kale (2015) argue for a deep-seated change in journalism curricula to make them more flexible and able to accommodate changes. Future media professionals should assimilate the fundamentals of journalism at the same time as they master digital journalism skills (p. 309). A programme revision is underway at the Department of Communication Arts (Journalism) at Divine Word University. A lack of human, economic and technical resources and a limited perception of international journalism standards, are some of the challenges faced by this kind of reform.

\section{Further research}

All these suggestions are based on good intentions. Unfortunately, before any kind of real implementation is conducted, proper research on the specificities of Papua New Guinea, its current situation regarding ICT infrastructure and access and a valid assessment of the country's needs is necessary. The lack of research in this area is alarming, as there is no accurate, or even approximate data that can guide decision-making. In order to move forward and ensure that Papua New Guinea stays in the picture of global digital participation, the public and private sectors in the country should consider digital access and literacy as a priority for development (Shade, 2003, p. 113). Research is imperative.

What is effective access? What is meaningful engagement with technology and how it can be achieved among Papua New Guineans? Shade suggests that research should promote a bottom-up approach, with public consultations (2003, p. 116). The way to bridge the digital divide must be created through the specific demands of Papua New Guinea, free from dominance by Western perspective and according to PNG's cultural terms. 


\section{Conclusion}

It seems clear that the expansion of the internet and ICTs is deepening inequalities among Papua New Guineans and between Papua New Guineans and developed countries. Because of the lack and quality of access in PNG, many people are deprived of opportunities and, consequently, denied the chance of a better life. However, more important than access to technology is the possession of digital skills, the fundamental abilities that allow people to meaningfully use technology to navigate the internet and participate in the online community. Beyond superficial operational and formal skills, the abilities that really contribute to the person's development in society and greatly affect their wellbeing are the information and strategic skills, those which allow them to use the internet and technology in a significant way.

When looking at the higher education panorama in PNG, the first question that arises is whether journalism students, have acquired these critical skills. University students are in a privileged position in comparison with other citizens in the country: they have access to technology, affordable or free connectivity to the internet and are being trained, at least at a basic level. However, they seem not to be actively engaging in a meaningful manner with the digital world. This should make us reflect and reconsider constructive ways to alleviate the problem and properly equip the students for the digital world.

Educators in PNG need to integrate the new technologies into teaching and learning practices with the aim of developing analytical and structural skills. The opportunity for Papua New Guinea to participate in global discussion and finally have its own voice is closer than ever but, at the same time, still far for many of our journalists and engaged citizens. From the offices and classrooms of journalism education institutions, more efforts should be made to ensure that future reporters in PNG have the necessary skills to enjoy the same advantages enjoyed by journalists anywhere else in the world.

\section{References}

Bloom, D. E., \& Rosovsky, H. (2006). Higher education in developing countries. In J. J. F. Forest \& P. G. Altbach (Eds.), International handbook of higher education (pp. 442-460). Dordrecht, The Netherlands: Springer.

Castells, M. (1999). An Introduction to the information age. In H. Mackay and T. O'Sullivan (Eds.), The media reader: Continuity and transformation (pp. 398-410). London: Sage.

CIA (Central Intelligence Agency - United States of America) (2015). Papua New Guinea country profile. In The world factbook. Retrieved from www.cia.gov/library/ publications/the-world-factbook/geos/pp.html

Coleman, M. (2015). Religious feminists and the digital divide. Journal of Feminist Studies in Religion, 31(2), 144-149.

DFAT (Australian Department of Foreign Affair and Trade) (2015) Papua New Guinea 
country brief. Official website. Retrieved from http://dfat.gov.au/geo/papua-newguinea/pages/papua-new- guinea-country-brief.aspx

DHERST (Department of Higher Education, Research, Science and Technology). (2015). National Higher and Technical Education Plan 2015-2024. Retrieved from www. dherst.gov.pg/wp-content/uploads/2015/04/NHTEP-2015-2024.pdf

Garnaut, R., \& Namaliu, R. (2010). PNG universities review report to prime ministers Somare and Rudd. Retrieved from www.ausaid.gov.au/country/pdf/png- universitiesreview.pdf

Goh, D. \& Kale, U. (2015). From print to digital platforms: A PBL framework for fostering multimedia competencies and consciousness in traditional journalism education. Journalism and Mass Communication Educator, 70(3), 307-323.

Internet World Stats (2015). Internet usage and population statistics for Oceania - 2015. Retrieved from www.internetworldstats.com/stats6.htm

James, J. (2012). Institutional and societal innovations in information technology for developing countries. Information Development, 28(3), 183-188.

Karthikeyan, P., \& Ramalingam, K. (2016). Abstracts: Education. In e-learning initiatives in delivering the undergraduate physiotherapy education program in Papua New Guinea (p. 23). Melbourne, VIC: APIAR.

Katz, I. R. (2007). Testing information literacy in digital environments: ETS's skills assessment.

Kolodziejczyk, I. (2012). Gender issues in access, application and attitudes toward information communication technology in higher education institutions in Papua New Guinea. Unpublished doctoral thesis, Divine Word University, Madang.

Papoutsaki, V., \& Rooney, R. (2006). Media, information and development in Papua New Guinea. Madang: Divine Word University Press.

Parent, I \& Cruickshank, N. (2009). The growth of the internet and knowledge networks, and their impact in the developing world. Information Development, 25(2), 91-98.

Park, E. \& Lee, S. (2015). Multidimensionality: Redefining the digital divide in the smartphone era. Info, 17(2), 80-96.

Radovanovic, D., Hogan, B. \& Lalic, D. (2015). Overcoming digital divides in higher education: Digital literacy beyond Facebook. New Media \& Society, 17(10), 1733-1749.

Rooney, D. (2004). Institutional accreditation in Papua New Guinea: Striving for quality. International Higher Education, 36(Summer), 23-25.

Schradie, J. (2011). The digital production gap: The digital divide and web 2.0 collide. Poetics, 39,145-168.

Selwyn, N. (2004). Reconsidering political and popular understandings of the digital divide. New Media \& Society, 6(3), 341-362.

Servon, L., \& Nelson, M. (2001). Community technology centres: Narrowing the digital divide in low-income, urban communities. Journal of Urban Affairs, 23, 3-4.

Shade, R. L. (2003). Here comes the DOT force: The new cavalry for equity. Gazette: The International Journal for Communication Studies, 65(2), 107-120.

Suwamaru, J. (2015). Aspects of mobile phone usage for socioeconomic development in Papua New Guinea. SSGM Discussion paper, 2015/11, Australian National University, Canberra.

Tagis, W. (2010). Office of Higher Education focuses on service delivery to 89 districts. Retrieved from www.ohe.gov.pg/index.php/executive/22-office-of-the- directorgeneral/9-office-of-higher-education-focuses-on-service-delivery-to-89-districts- .html

UN Data (2015). Papua New Guinea Country. Retrieved from http://data.un.org/CountryProfile.aspx?crName=papua\%20new\%20guinea 
UNDP (United Nations Development Programme). (2014). National human development report Papua New Guinea-From wealth to wellbeing: Translating resource revenue into sustainable human development. Retrieved from http://hdr.undp.org/sites/default/ files/2014_png_national_human_development_report.pdf, viewed 02/07/2015

UNDP (United Nations Development Programme). (2015). Papua New Guinea official website. Retrieved from www.pg.undp.org

Van Deursen, A. \& Van Dijk, J. (2010). Internet skills and the digital divide. New Media \& Society, 13(6), 893-911.

Watson, A. H. A. (2009). 'We would have saved her life': Mobile telephony in an island village in Papua New Guinea. E-journalists.com.au, 106-127.

Watson, A. H. A. (2011). The mobile phone: The new communication drum of Papua New Guinea. Unpublished doctoral thesis. Brisbane: Queensland University of Technology.

WHO (World Health Organisation) (2015). Countries: Papua New Guinea. Retrieved from www.who.int/countries/png/en/.

World Bank. (2009). World Bank data: Papua New Guinea. Retrieved from http://data. worldbank.org/country/papua-new-guinea

World Bank. (2011). World Bank data: Papua New Guinea. Retrieved from http://data. worldbank.org/country/papua-new-guinea

World Bank. (2015). World Bank data: Papua New Guinea. Retrieved from http://data. worldbank.org/country/papua-new-guinea

Yu, L. (2006). Understanding information inequality: Making sense of the literature of the information and digital divides. Journal of Librarianship and Information Science, 38(4), 229-252.

Maria Sagrista is digital media lecturer in the Department of Communication Arts, Faculty of Arts and Social Sciences, Divine Word University, Madang, Papua New Guinea. She was among a group of Pacific media educators and trainers brought to New Zealand for the World Journalism Education Congress (WJEC) conference at Auckland University of Technology on 14-16 July 2016 by sponsorship from the NZ Institute of Pacific Research. mariarsagrista@gmail.com

Patrick Matbob is senior lecturer in the Department of Communication Arts, Faculty of Arts and Social Sciences, Divine Word University, Madang, Papua New Guinea. 